\title{
TGF- $\beta$ activity protects against inflammatory aortic aneurysm progression and complications in angiotensin II-infused mice
}

\author{
Yu Wang, ${ }^{1}$ Hafid Ait-Oufella, ${ }^{1,2}$ Olivier Herbin, ${ }^{1}$ Philippe Bonnin, ${ }^{3}$ Bhama Ramkhelawon,, \\ Soraya Taleb, ${ }^{1}$ Jin Huang, ${ }^{1}$ Georges Offenstadt, ${ }^{2}$ Christophe Combadière, ${ }^{4}$ Laurent Rénia, ${ }^{5}$ \\ Jason L. Johnson, ${ }^{6}$ Pierre-Louis Tharaux,, ${ }^{1}$ Alain Tedgui,, ${ }^{1}$ and Ziad Mallat ${ }^{1}$ \\ ${ }^{1}$ INSERM U970, Paris Cardiovascular Research Center, Université Paris-Descartes and Assistance Publique-Hôpitaux de Paris, Paris, France. \\ ${ }^{2}$ Service de Réanimation Médicale, Hôpital St-Antoine, Paris, France. ${ }^{3}$ Service d'Explorations Fonctionnelles, Hôpital Lariboisière, Paris, France. \\ ${ }^{4}$ INSERM U543, Université Pierre et Marie Curie, Paris, France. ${ }^{5}$ Singapore Immunology Network, Agency for Science, \\ Technology and Research, Biopolis, Singapore. ${ }^{6}$ Bristol Heart Institute, University of Bristol, Bristol, United Kingdom.
}

\begin{abstract}
Complicated abdominal aortic aneurysm (AAA) is a major cause of mortality in elderly men. Ang II-dependent TGF- $\beta$ activity promotes aortic aneurysm progression in experimental Marfan syndrome. However, the role of TGF- $\beta$ in experimental models of AAA has not been comprehensively assessed. Here, we show that systemic neutralization of TGF- $\beta$ activity breaks the resistance of normocholesterolemic C57BL/6 mice to Ang II-induced AAA formation and markedly increases their susceptibility to the disease. These aneurysms displayed a large spectrum of complications on echography, including fissuration, double channel formation, and rupture, leading to death from aneurysm complications. The disease was refractory to inhibition of IFN- $\gamma$, IL-4, IL-6, or TNF- $\alpha$ signaling. Genetic deletion of T and B cells or inhibition of the CX3CR1 pathway resulted in partial protection. Interestingly, neutralization of TGF- $\beta$ activity enhanced monocyte invasiveness, and monocyte depletion markedly inhibited aneurysm progression and complications. Finally, TGF- $\beta$ neutralization increased MMP-12 activity, and MMP-12 deficiency prevented aneurysm rupture. These results clearly identify a critical role for TGF- $\beta$ in the taming of the innate immune response and the preservation of vessel integrity in $\mathrm{C} 57 \mathrm{BL} / 6$ mice, which contrasts with its reported pathogenic role in Marfan syndrome.
\end{abstract}

\section{Introduction}

Abdominal aortic aneurysm (AAA) is an age-associated disease that affects approximately $5 \%$ of elderly men and is responsible for a significant number of deaths in Western countries (1). At present, the incidence of AAA is still increasing, which suggests that the public health measures that have helped reduce the burden of occlusive cardiovascular disease are not effective for AAA. In addition, with the possible introduction of screening for AAA, large numbers of small aneurysms will be diagnosed over the next decade (2). Natural history and epidemiological studies suggest that smoking cessation and control of blood pressure should reduce the number of patients developing AAA and its progression rate (reviewed in ref. 3). Still, surgery is currently the only therapy for individuals with AAA, and the intervention is costly and associated with high morbidity and mortality. No drug treatments have been approved for use in this disease $(4,5)$, which greatly highlights the need for a better understanding of disease pathophysiology in order to implement novel management procedures and therapeutic strategies.

While initial studies have focused on the structural weakness of the vessel wall, indirectly suggesting a protective role for a matrix-promoting cytokine such as TGF- $\beta$ against disease development, recent studies on defined forms of ascending aortic aneurysm have led to a concept shift in our understanding of the pathophysiology of aneurysm formation. Studies using transgenic mouse models of Marfan syndrome showed a critical pathogenic role for increased TGF- $\beta$ signaling in promoting abnormal vessel remodeling, dilatation,

Conflict of interest: The authors have declared that no conflict of interest exists. Citation for this article: J Clin Invest. 2010;120(2):422-432. doi:10.1172/JCI38136. and aneurysm expansion (6). The results were confirmed by studies showing upregulation of TGF- $\beta$ signaling in patients with Marfan disease and by the identification of TGFBR1 and TGBR2 gene mutations in patients with Loeys-Dietz syndrome, thought to be responsible for increased TGF- $\beta$ activity (7-10). These studies have led at least some investigators to suggest that monogenic disorders such as Marfan and Loeys-Dietz syndromes are good genetic models for the pathogenesis of other forms of aortic aneurysm (11). This is in part supported by the finding of increased vascular TGF- $\beta$ expression and Smad-2 phosphorylation in syndromic and nonsyndromic aneurysms of the ascending aorta (12). However, the mechanisms linking increased TGF- $\beta$ activity to aneurysm formation have not been determined, and, importantly, the precise and direct role of TGF- $\beta$ activity in inflammatory forms of the disease is still unknown.

While aneurysm formation in Marfan syndrome is associated with deposition of an abnormal extracellular matrix during vessel development, careful examination of human pathological specimens and animal models indicates that aortic dissection/aneurysm is characterized by local destruction of the extracellular matrix and thinning of the vascular wall, associated with a prominent inflammatory cell infiltrate, which is almost absent in Marfan syndrome (3, 13-15). Thus, we hypothesized that in inflammatory forms of abdominal aortic dissection/aneurysm, matrix-promoting and antiinflammatory properties of TGF- $\beta$ link the control of the pathogenic immune response to tissue remodeling and repair after injury, thereby acting as a critical negative modulator of disease progression.

Ang II-induced AAA is a validated model of aneurysm formation in mice (16); has been associated with increased expression of TGF- $\beta$ (17); and is prevented, like murine Marfan syndrome (6), by 
A
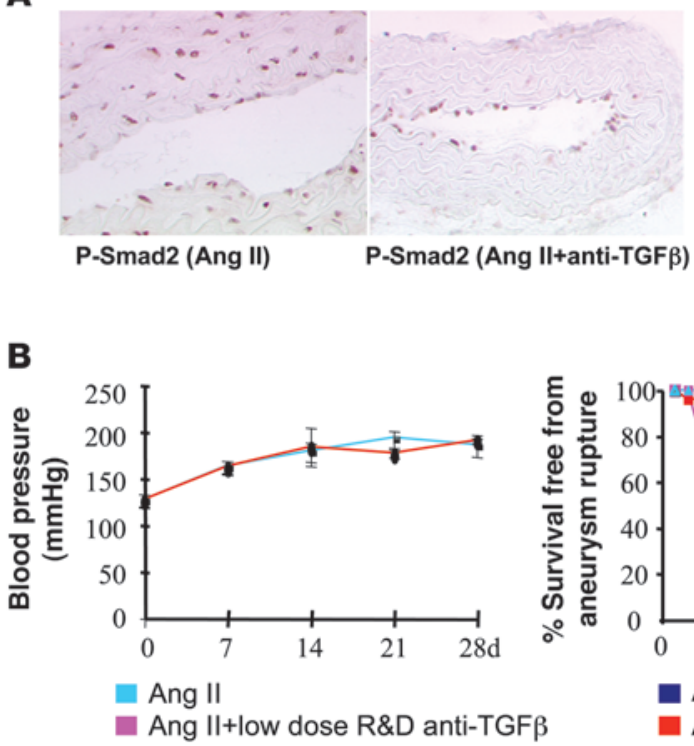

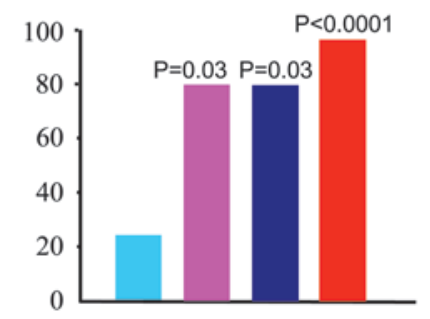

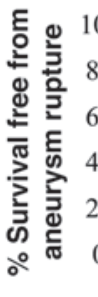

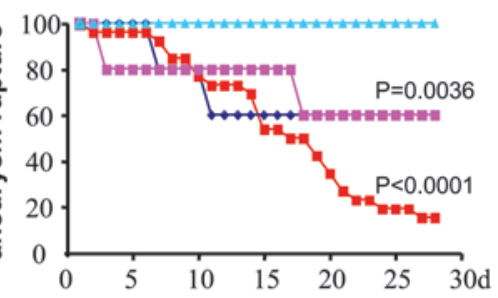

Ang II+low dose $2 \mathrm{G} 7$ anti-TGF $\beta$ Ang II+high dose $2 \mathrm{G} 7$ anti-TGF $\beta$

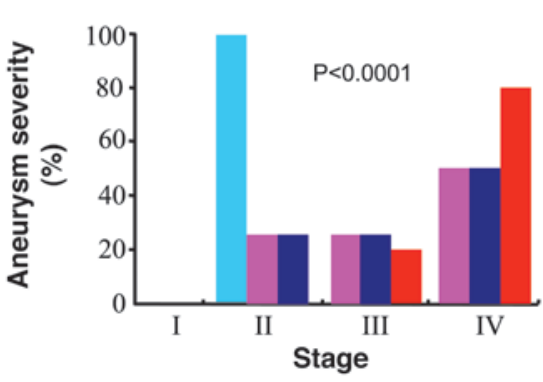

Figure 1

Neutralization of TGF- $\beta$ activity induces a highly permissive state for Ang II-induced aortic aneurysm formation and complications. (A) Phosphorylation of Smad-2 (nuclear red staining) is abrogated in the vascular media and adventitia of aortas recovered 3 days after intraperitoneal administration of $500 \mu \mathrm{g}$ of anti-TGF- $\beta$ antibody (2G7 clone). Note that at this time point, the media and adventitia are infiltrated by macrophages (see Figure 3E). Original magnification, $\times 200$ for Ang II and $\times 100$ for Ang II + anti-TGF- $\beta$. Right panel: Serum TGF- $\beta$ is barely detectable in mice 3 days after $500 \mu \mathrm{g}$ of anti-TGF- $\beta$ antibody compared with nontreated animals. Results are representative of 2 different experiments. (B) Neutralization of TGF- $\beta$ activity did not alter blood pressure levels (left panel). Right panel: Effects of low-dose anti-TGF- $\beta$ antibody (R\&D Systems, $n=5$; or 2G7 clone, $n=5$ ) or high-dose $2 \mathrm{G} 7$ clone $(n=26)$ on survival from ruptured aortic aneurysm, compared with mice that received Ang II in the absence of TGF- $\beta$ neutralization $(n=29)$. (C) Quantification of aneurysm incidence and severity (increasing severity from stage I to stage IV as described in ref. 52) in all groups of mice. Stage IV was attributed to ruptured aneurysms.

treatment with Ang II receptor type I antagonists (18). Moreover, Ang II type I receptor and angiotensin-converting enzyme (ACE) DD polymorphisms are associated with AAA in humans $(19,20)$. Therefore, this model was appropriate for testing the role of TGF- $\beta$ activity in AAA formation.

\section{Results}

Systemic neutralization of TGF- $\beta$ activity breaks the resistance of normocholesterolemic C57BL/6 mice to Ang II-induced aortic aneurysm formation. While examining the role of systemic neutralization of TGF- $\beta$ activity on Ang II-induced glomerulonephritis, we discovered the occurrence of unexplained death beginning after the first week of treatment in the group of mice treated with anti-TGF- $\beta$ antibody compared with mice treated with isotypematched control antibody or anti-IFN- $\gamma$ antibody. The mice of the latter 2 groups survived the 4 weeks of treatment without complications (data not shown). Necropsies identified the cause of deaths as vascular rupture upon complicated and advanced AAA in the group of mice treated with anti-TGF- $\beta$ antibody. We therefore initiated a study to confirm and understand the mechanisms underlying this previously unrecognized vascular phenotype.

The results seemed at odds with data showing increased TGF- $\beta$ signaling as a driving force in the pathogenesis of Marfan syndrome (7, 9, $10)$, confirmed later by mechanistic studies showing that inhibition of TGF- $\beta$ signaling prevents vessel dilatation and aneurysm formation in a mouse model of Marfan disease (6). We therefore used 2 different anti-TGF- $\beta$ antibodies, including the same anti-TGF- $\beta$ antibody (AB-100-NA, R\&D Systems) shown to inhibit aortic aneurysm formation in a mouse model of Marfan disease (6). Three days after injection, anti-TGF- $\beta$ antibody almost abrogated serum TGF- $\beta$ activity and vascular Smad-2 phosphorylation within the media and adventitia (infiltrated at this time point by macrophages; see below), with little effect on endothelial cells (Figure 1A). Thus, to sustain an efficient blockade of TGF- $\beta$ activity, the protocol involved administration of anti-TGF- $\beta$ antibody every 3 days. This treatment did not alter the blood pressure levels in response to Ang II infusion (Figure 1B). Interestingly, while only $20 \%$ of Ang II-infused C57BL/ 6 mice developed uncomplicated AAA, administration of anti-TGF- $\beta$ antibody (R\&D Systems antibody or $2 \mathrm{G} 7$ clone) at $10 \mathrm{mg} / \mathrm{kg}$ twice a week to Ang II-infused mice led to the development of AAA in $80 \%$ of the mice, with $40 \%$ mortality from aneurysm rupture (Figure 1, B and C). A lower dose of anti-TGF- $\beta$ antibody (R\&D Systems) $-10 \mathrm{mg} / \mathrm{kg}$ every 2 weeks as in one Marfan experiment (6) or $1 \mathrm{mg} / \mathrm{kg}$ the day before placement of Ang II and the day after Ang II as in a recent experiment (21) - or administration of this neutralizing antibody in the absence of Ang II did not induce AAA formation (data not shown). A higher dose of anti-TGF- $\beta$ antibody (2G7 clone, $20 \mathrm{mg} / \mathrm{kg}$ every 3 days for 15 days followed by $6 \mathrm{mg} / \mathrm{kg}$ every 3 days for 12 days) led to a further increase in the incidence of AAA $(90 \%)$ and to a marked increase in AAA severity (Figure 1C) and complications, leading to $80 \%$ mortality from AAA rupture (Figure 1B). In addition to AAA, rupture of the thoracic aorta and intrathoracic hemorrhage leading to animal death occurred in $15 \%$ of anti-TGF- $\beta$-treated, Ang II-infused mice, in the presence or absence of abdominal aortic rupture. It could be argued that TGF- $\beta$ inhibition before disease initiation could be protective. However, of the 5 mice that received anti-TGF- $\beta$ antibody (high dose) at day -7 and day -3 before Ang II infusion, 2 died from AAA rupture before the end of the experiment. At the end of the experiment 
A

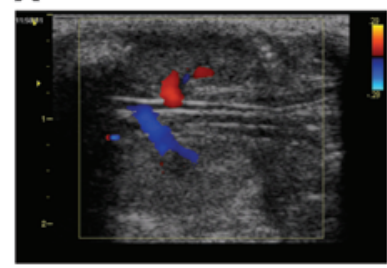

Normal aorta

D

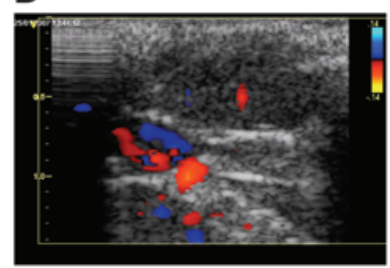

E

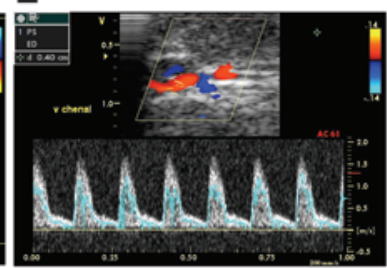

Fusiform abdominal aortic aneurysm

$\mathbf{F}$

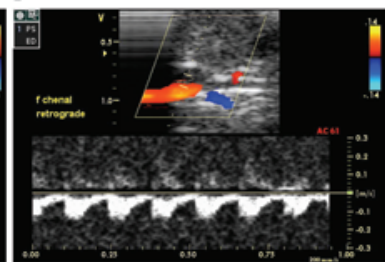

Aneurysm dissection with double channel formation

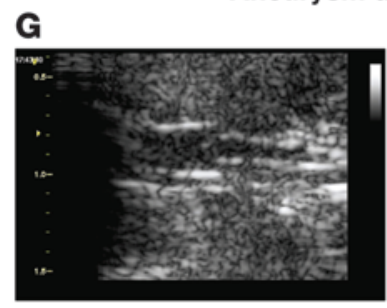
H

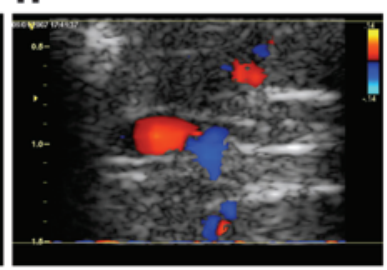

I

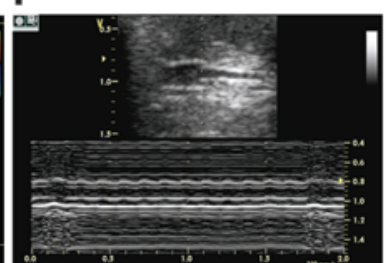

Complete rupture of abdominal aortic aneurysm

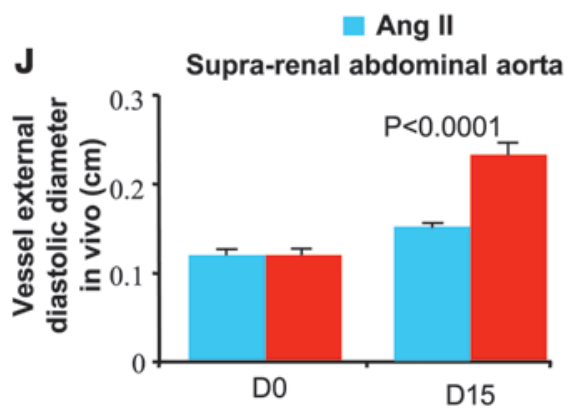

Ang II+2G7 anti-TGF $\beta$

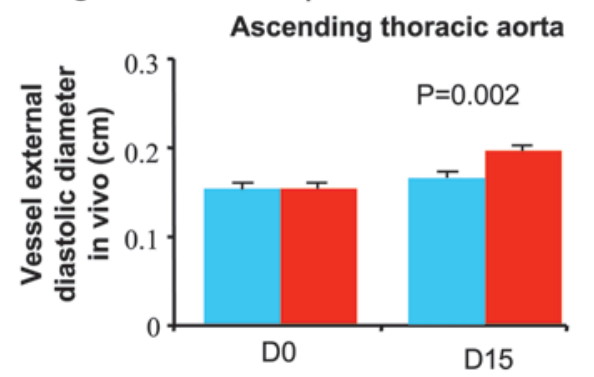

\section{Figure 2}

Two-dimensional color-coded ultrasound imaging of aortic aneurysm development and complications in mice. (A) Two-dimensional (2D) ultrasound imaging of a normal abdominal aorta visualized between the left (top) and the right (bottom) kidneys. (B) 2D color-coded Doppler imaging revealed a fusiform dilation of the upper renal abdominal aorta. M-mode showed increased diastolic and systolic diameters (C). (D-F) Dissected aneurysm of the upper renal abdominal aorta. Color-coded Doppler imaging revealed a dissection with 2 lumens: the true lumen was coded in red and showed a forward blood flow toward the renal arteries and the suprarenal abdominal aorta; the second lumen, colored in blue, showed a backward blood flow (D). Pulsed Doppler revealed an accelerated forward blood flow in the true lumen (E) and a backward blood flow in the second lumen (F), which was suggestive of false channel formation. (G-I) Complete disintegration of the distal part of an aortic aneurysm (G). 2D color-coded Doppler imaging evidenced the inferior limit of the aneurysm just upstream of the emergence of the right renal artery coded in blue $\mathbf{( H )}$. Targeted M-mode is shown in I. (J) Histograms show determination of vessel diameter in vivo using ultrasound imaging at day 0 and day 15 after the beginning of treatment. Vessel dilatation at the suprarenal level was markedly pronounced in the mice that received antiTGF- $\beta$ antibody ( $n=7$ for Ang II and $n=17$ for Ang II + anti-TGF- $\beta$ ). We also found a significant dilatation of the ascending aorta at day 15 in the anti-TGF- $\beta$ group ( $n=7-9$ per group). (day 28), 1 of the 3 surviving mice showed a stage III AAA, the other 2 mice being free of AAA. Thus, inhibition of TGF- $\beta$ activity prior to disease initiation still enhances susceptibility to AAA, although to a lesser extent than continuous treatment.

The results were not specific to normocholesterolemic mice. Systemic neutralization of TGF- $\beta$ activity in spontaneously hypercholesterolemic Apoe ${ }^{-/-}$mice, known to be susceptible to Ang IIinduced AAA (16), also led to a significant increase in both AAA incidence and severity (Supplemental Figure 1; supplemental material available online with this article; doi:10.1172/JCI38136DS1).

Unlike the results obtained in a mouse model of Marfan disease, these findings clearly identify a critical role for TGF- $\beta$ activity in protection against Ang II-induced aneurysm formation in C57BL/6 mice.

AAAs induced in the presence of Ang II and anti-TGF- $\beta$ antibody display features of aneurysm complications seen in buman $A A A$. We subjected a subgroup of mice to color-coded and pulsed Doppler ultrasound imaging once a week. This allowed us to gain insight into the natural history of aneurysm formation and vascular rupture in vivo. Interestingly, all features of human AAA were recapitulated in the present mouse model on an accelerated time scale of less than 4 weeks. The vascular features ranged from simple vascular dilatation in the early phases of disease development (generally during the first week) (Figure 2, B and C) to signs of dissection with or without double channel formation (Figure 2, D-F) or even in vivo complete aortic rupture, captured a few moments or hours before animal death (Figure 2, G-I). Serial ultrasound imaging allowed us to determine the progression of vessel dilatation in the first 2 weeks of treatment. As shown in Figure 2, mice treated with Ang II and anti-TGF- $\beta$ antibody showed a marked and quick vessel dilatation of the suprarenal abdominal aorta compared with Ang IItreated mice. We also detected a modest but significant dilatation of the ascending aorta in anti-TGF- $\beta$-treated mice (Figure 2J).

AAAs induced in the presence of Ang II and anti-TGF- $\beta$ antibody are associated with smooth muscle cell death, elastin degradation, and enhanced vascular inflammation. Ang II-induced aneurysm formation in Apoe-/mice is associated with vascular thinning and inflammation (13). We therefore examined the role of TGF- $\beta$ activity in the preservation of medial smooth muscle cells, extracellular matrix, and the modulation of inflammatory cell recruitment to the vessel wall. Enhanced susceptibility of Ang II-infused, anti-TGF- $\beta$-treated mice to AAA formation was associated with a marked increase in the accumulation 
A

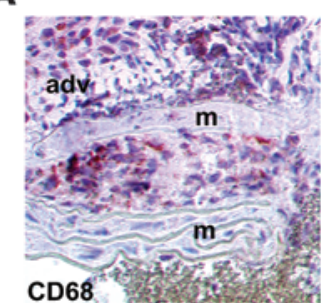

B

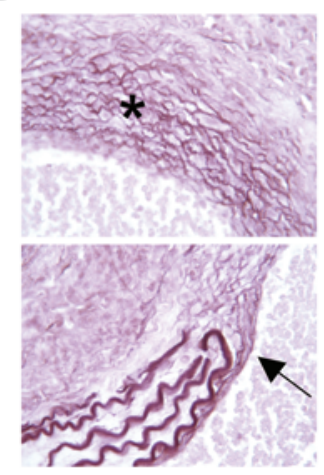

E

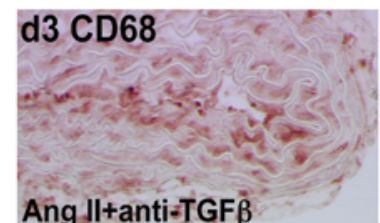

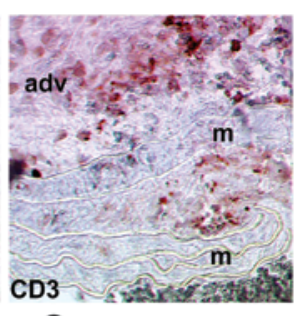

C

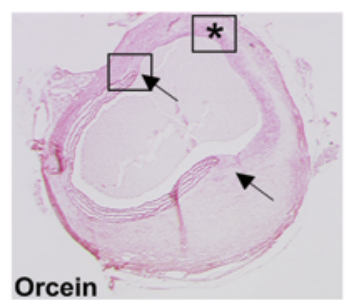

Orcein

Ang II+anti-TGF $\beta$

Ang II

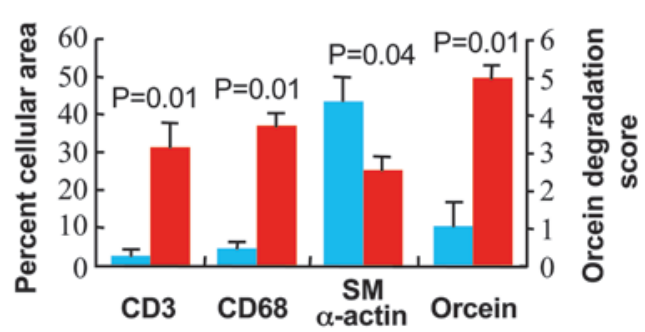

D

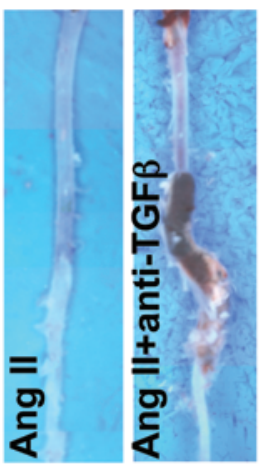

$\mathbf{F}$
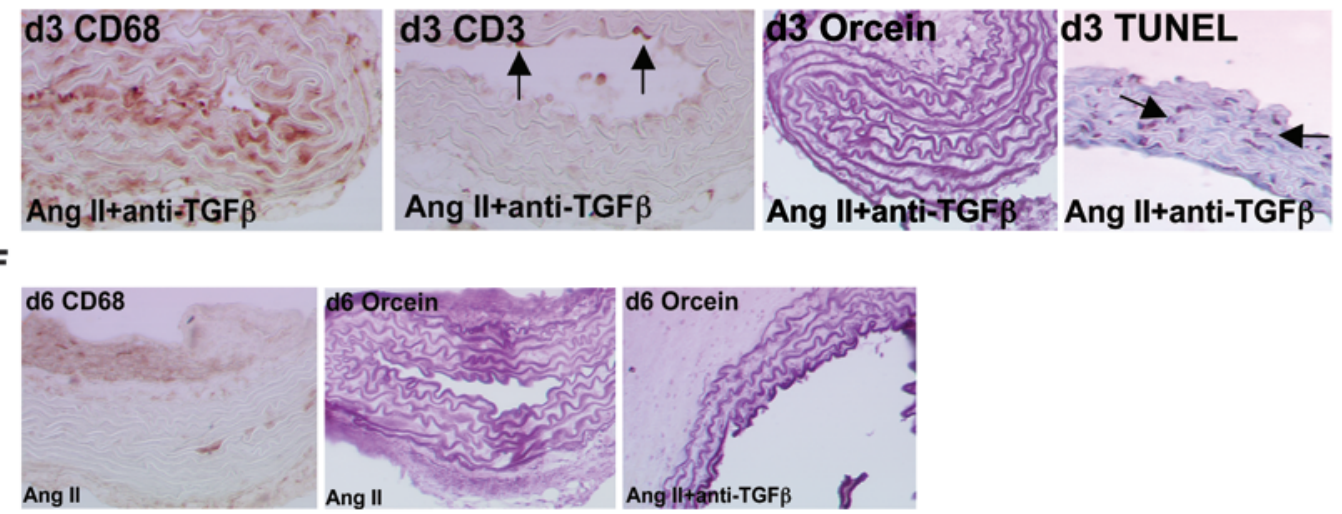

Figure 3

Characterization of Ang II-induced aortic aneurysms in mice treated with anti-TGF- $\beta$ antibody. (A) Representative photomicrographs of macrophage (CD68), T lymphocyte (CD3), and elastin (orcein) stainings of aortic aneurysms from mice infused with Ang II and treated with anti-TGF- $\beta$ antibody. adv, adventitia; $\mathrm{m}$, media. Arrows show the sites of complete elastin degradation. (B) Higher magnifications of vessel areas indicated in the right panel of A. Asterisk indicates advanced elastin disruption of all lamellae. Arrow shows the edge of degraded elastin lamellae. (C) Quantification ( $n=5$ mice per group) of smooth muscle cell ( $\alpha$-actin) content, elastin (orcein) degradation, as well as macrophage and T lymphocyte infiltration. (D) Representative photomicrographs of aortas recovered from mice infused with Ang II in the presence or absence of anti-TGF- $\beta$ antibody. (E) Aortic tissue sections recovered after 3 days of treatment and stained for the presence of macrophages (CD68, brown), T lymphocytes (CD3, punctuate red-brown, arrows), elastin (orcein), or apoptotic cells (TUNEL, red-brown nuclei, arrows). Note that macrophage infiltration preceded T cell accumulation and overt elastin degradation and coincided with the occurrence of VSMC death. (F) Staining for macrophages (CD68) and elastin (orcein) after 6 days of treatment. Rare macrophages and no elastin degradation were observed in the Ang II group. However, intense elastin degradation ( $2.4 \pm 0.4$ elastin lamellae lost) was detected at this time point in the Ang II + anti-TGF- $\beta$ group. Data are representative of 5 mice per time point and per group. Original magnification, $\times 400$ (A, except right panel: $\times 40) ; \times 400(\mathbf{B}) ; \times 100(\mathbf{E}$, except right panel: $\times 200) ; \times 200(\mathbf{F})$.

of macrophages and $\mathrm{T}$ lymphocytes within the adventitia and their infiltration within the media (Figure 3A), along with an important loss of medial smooth muscle cells and focal yet intense elastin degradation, ultimately leading to medial dissection and aortic rupture (Figure 3, A-D). Analysis of earlier time points before overt aneurysm formation and medial dissection indicated early accumulation of macrophages in the group treated with Ang II plus anti-TGF- $\beta$ $(10.2 \% \pm 1.8 \%$ of vessel area; Figure $3 \mathrm{E}, n=5)$ compared with the Ang II group (less than $0.5 \%$; Figure $3 \mathrm{~F}, n=5$ ), which preceded $\mathrm{T}$ cell infiltration (CD3 staining in Figure 3E) and the beginning of elastin degradation and the occurrence of smooth muscle cell apoptosis (orcein staining in Figure 3, E and F, and TUNEL staining in Figure $3 \mathrm{E})$. These data are supported by in vitro findings showing enhanced apoptotic cell death of aortic smooth muscle cells in the presence of anti-TGF- $\beta$ antibody (Supplemental Figure 2). Thus, our findings support a critical role for TGF- $\beta$ activity in the taming of the inflammatory response and the preservation of medial smooth muscle cells, producing a protective extracellular matrix. 
A

Ang II+anti-TGF $\beta$

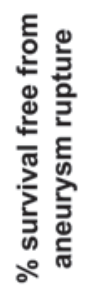

B

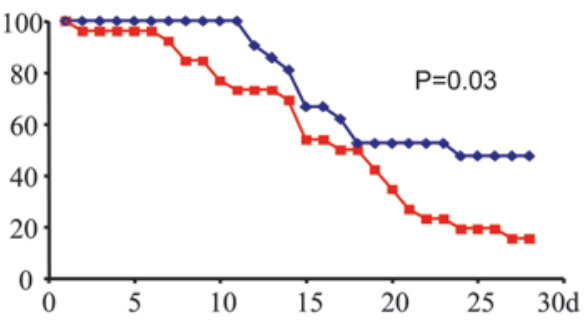

Ang II+anti-TGF $\beta+$ anti-IFN $\gamma$

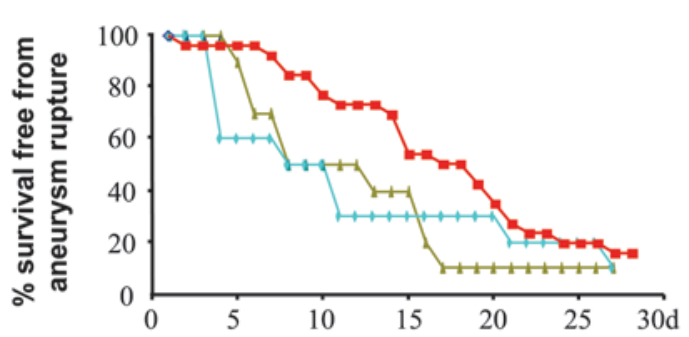

C

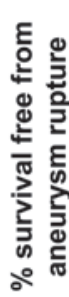

Ang II+anti-TGF $\beta, \| 6^{-1-}$ mice

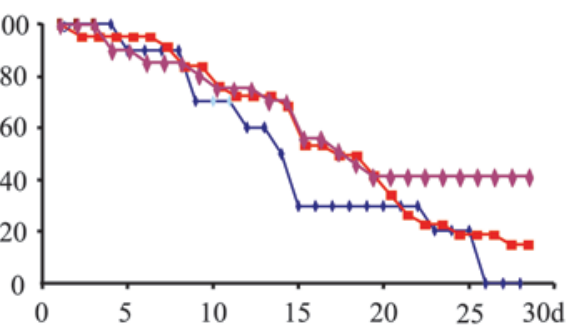

Ang II+anti-TGF $\beta$, Rag2 $^{-/}$mice

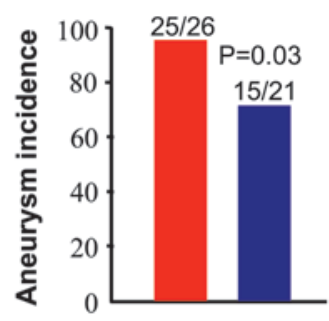

Ang $I++a n t i-T G F \beta, \| 4^{-/}$mice

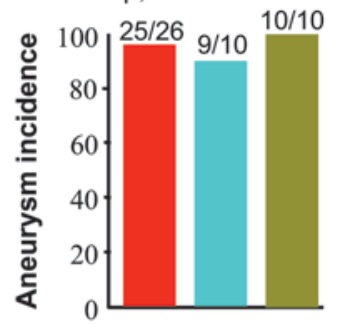

Ang II+anti-TGF $\beta+$ Infliximab

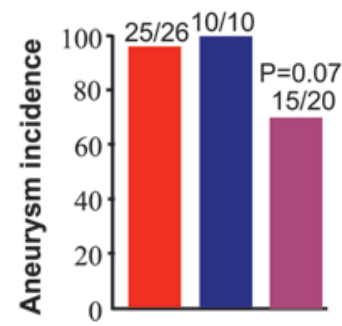

\section{Figure 4}

Ang II-induced aortic aneurysms in mice treated with anti-TGF- $\beta$ antibody are not prevented by inhibition of IFN- $\gamma$, IL-4, IL-6, or TNF- $\alpha$ signaling. Kaplan-Meier curves of survival free from aneurysm rupture and quantification of aortic aneurysm incidence in all groups of mice. (A) Deficien-

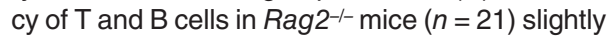
but significantly reduced aneurysm incidence and severity compared with controls $(n=26)$. (B and C) However, inhibition of IFN- $\gamma(n=10)$ or TNF- $\alpha$ $(n=20)$ signaling or genetic deficiency in IL-4 $(n=10)$ or IL-6 $(n=10)$ did not afford protection. Results for the Ang II + anti-TGF- $\beta$ group are shown only for comparison, but the experiments were not conducted simultaneously with the other groups of mice.
Th1 and Th2 responses are dispensable for AAA formation in mice treated with Ang II and anti-TGF- $\beta$ antibody. TGF- $\beta$ is a critical regulator of Th1 and Th2 differentiation (22), and, depending on the model of aneurysm formation, both $\mathrm{T}$ helper cell responses have been shown to contribute to disease development $(23,24)$. However, to our surprise, systemic administration of a neutralizing anti-IFN- $\gamma$ antibody or genetic deletion of IL-4 did not protect against disease development or severity (Figure 4B). Rag2-deficient mice were only partially protected from aneurysm formation and complications (Figure 4A), suggesting a secondary role for $\mathrm{T}$ cells in this disease. Further studies should address the roles of other $\mathrm{T}$ cell subsets, Th17 cell and/or Treg responses, in this context.

Monocytes/macrophages are critical mediators of AAA formation in mice treated with Ang II and anti-TGF- $\beta$ antibody. We next addressed the role of the innate immune response. IL- 6 is highly induced in response to Ang II stimulation (25) and has been involved in elastase-induced aneurysm formation (26). TNF- $\alpha$ is not only a Th1 product but is also produced at high levels by innate immune cells and expressed in AAA. However, systemic neutralization of TNF- $\alpha$ using infliximab or genetic deletion of IL- 6 did not alter aneurysm formation or severity in Ang II-infused, anti-TGF- $\beta$-treated mice (Figure 4C).

Despite these results, our findings of early attraction and infiltration of macrophages within the vessel wall, which coincided with smooth muscle cell apoptosis and the beginning of matrix degradation, clearly suggested a pathogenic role for this cell subset in disease initiation. Consistent with this hypothesis, we found that $\mathrm{C} \times 3 \mathrm{cr} 1$ deficiency provided partial but significant protection against aneurysm complications (Supplemental Figure 3). Similar results were obtained with $c x 3 c r 1 / C c l 2$-deficient mice (data not shown). However, the protection was still partial, suggesting that other chemokine-related pathways and monocyte/macrophage functions may be important.

Therefore, in order to directly address the role of monocytes/ macrophages in aneurysm development, we depleted circulating monocytes with clodronate-containing liposomes (Figure 5A). Clodronate-liposomes were administered intravenously every 3 days. In pilot experiments, we observed a $60 \%$ reduction in circulating $7 / 4^{\text {hi }}$ and $7 / 4^{\text {int }}$ monocytes ("inflammatory" monocyte subset) and a $50 \%$ reduction of $7 / 4^{\text {lo }}$ and $7 / 4^{-}$monocytes ("resident" monocyte subset) after 2 days of clodronate treatment (1 clodronate injection) compared with mice treated with PBS-containing liposomes (Figure 5A). Two consecutive clodronate injections resulted, at day 5 , in a sustained $60 \%$ reduction in circulating $7 / 4^{\text {hi }}$ and $7 / 4^{\text {int }}$ monocytes and a further profound decrease ( $80 \%$ reduction) in $7 / 4^{\text {lo }}$ and $7 / 4^{-}$monocytes (Figure $5 \mathrm{~A}$ ), which was sustained over 2 weeks of treatment (data not shown). Clodronate treatment also led to a near disappearance of spleen monocytes (data not shown), abrogation of IL-12, and a marked reduction in IL-10 production by LPS/IFN- $\gamma$-stimulated splenocytes (Figure 5A). Neutrophil count was not significantly altered by clodronate administration.

We therefore examined the effects of clodronate-induced monocyte depletion on aneurysm formation. To avoid undesirable effects of prolonged treatment with clodronate-liposomes, mice were sacrificed after 18 days of treatment, and aneurysm formation 
A

A
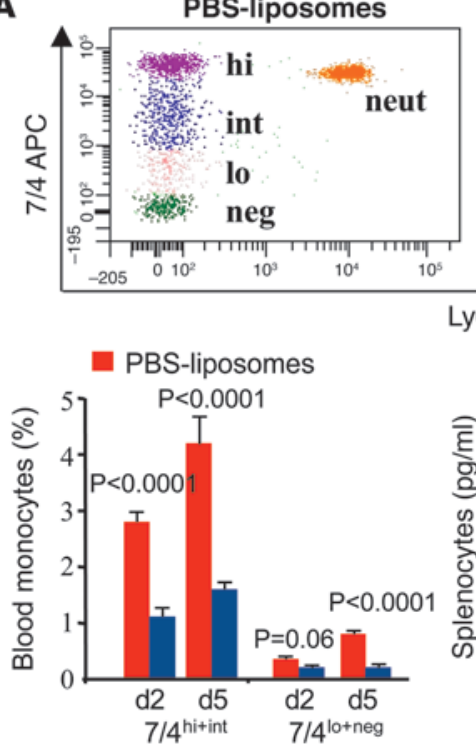

B

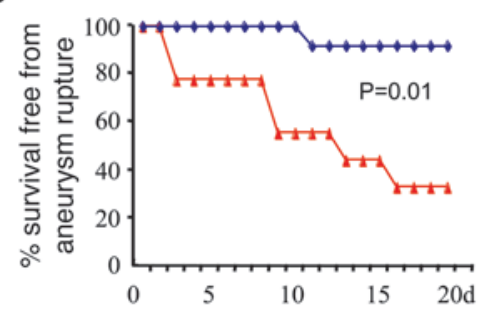

Clodronate-liposomes

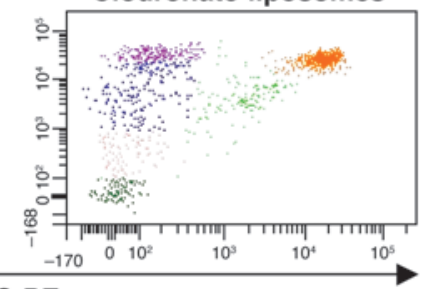

Ly6G PE

- Clodronate-liposomes

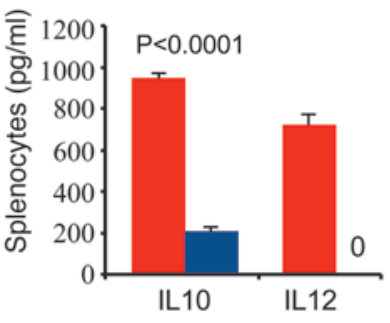

C
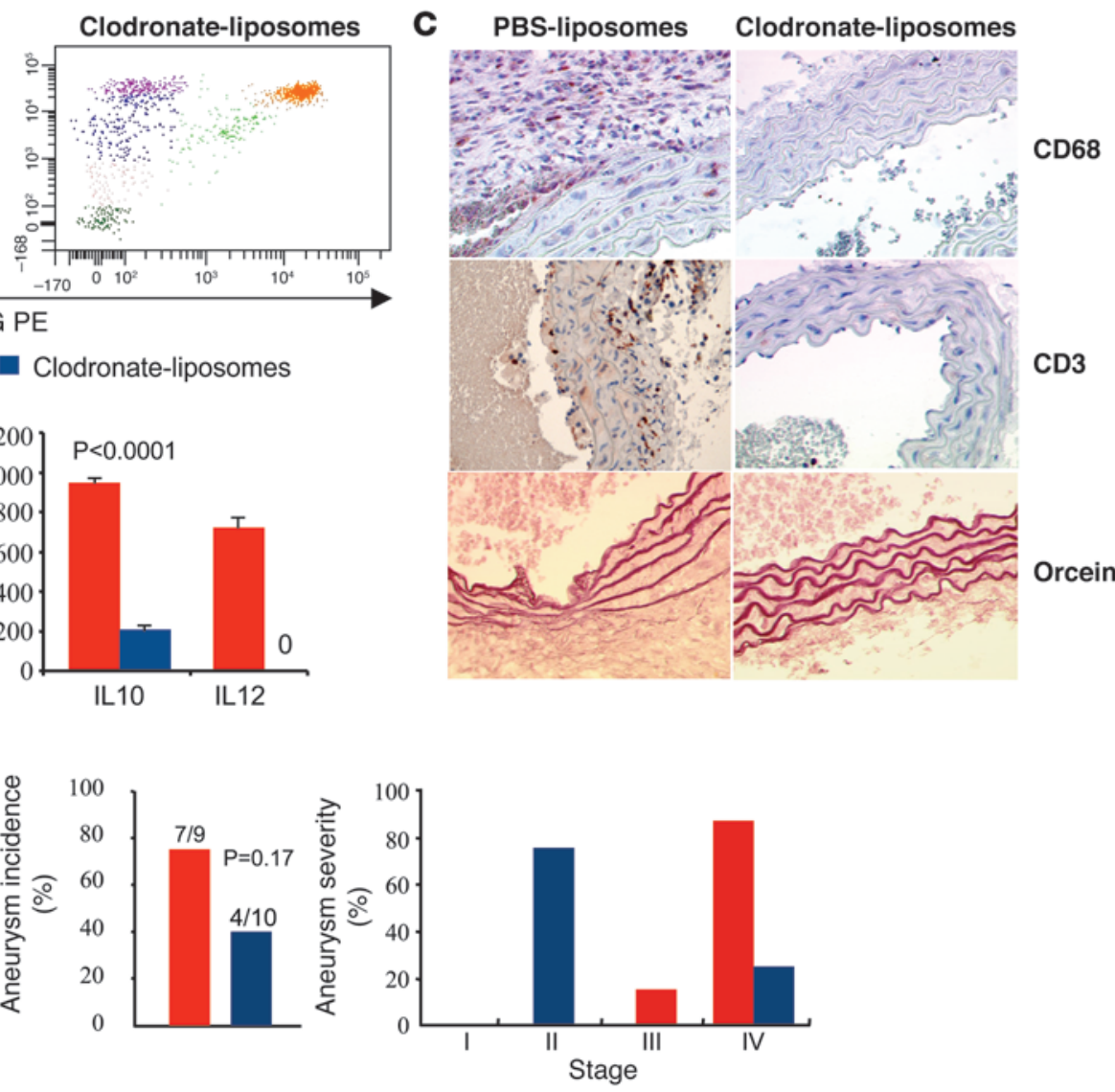

\section{Figure 5}

Ang II-induced aortic aneurysm in mice treated with anti-TGF- $\beta$ antibody is prevented by monocyte depletion. (A) Representative examples of flow cytometry and quantitative analysis of the various monocyte subsets in mice treated with either PBS- or clodronate-containing liposomes. Clodronate treatment significantly reduced the number of all monocyte subsets, with no significant effects on neutrophil count. Results are mean \pm SEM of 6 mice per group. Clodronate treatment also reduced IL-10 and abrogated IL-12 production by LPS/INF- $\gamma$-treated splenocytes recovered from clodronate-treated animals (results are representative of 3 mice per group). (B) Kaplan-Meier curves of survival free from aneurysm rupture and quantification of aortic aneurysm incidence and severity in mice (Ang II + anti-TGF- $\beta$ ) treated with either PBS- $(n=9)$ or clodronate-liposomes $(n=10)$. $P=0.026$, clodronate- versus PBS-liposomes. (C) Representative photomicrographs of macrophage (CD68) and T lymphocyte (CD3) infiltration as well as elastin content (orcein) of the aortic vessel wall in mice treated with either PBS- or clodronate-liposomes. Original magnification, $\times 400$.

and severity were compared with those in mice treated with PBScontaining liposomes. Monocyte depletion led to a profound, $90 \%$ reduction in mortality from ruptured aneurysm, which was due to a significant reduction in the severity of AAA (Figure 5B). Pathological analysis of the aorta in mice treated with clodronate-liposomes revealed a near absence of macrophage infiltration $(0.2 \% \pm 0.1 \%)$, along with a profound decrease in $\mathrm{T}$ cell accumulation ( $\mathrm{T}$ cell positivity, $1.5 \% \pm 0.5 \%$ ) and a preservation of elastin lamellae (elastin score, $0.75 \% \pm 0.25 \%$ ) (Figure $5 \mathrm{C}$ ). These findings clearly identify a central role for monocyte/macrophage activation in the orchestration of vascular inflammation and the promotion of vascular aneurysm and support a critical role for TGF- $\beta$ activity in the control of this pathogenic innate immune response.

Increased activation of matrix-degrading activity in aortas of mice treated with Ang II and anti-TGF- $\beta$ antibody and its abrogation by monocyte/ macrophage depletion. Monocytes/macrophages produce matrixdegrading enzymes that could contribute to medial destruction, aneurysm formation, and rupture. Ang II infusion slightly increased aortic gelatinolytic activity (Figure 6). However, we found a marked upregulation of gelatinolytic activity in abdomi- nal aortic segments of Ang II-infused mice treated with neutralizing anti-TGF- $\beta$ antibody (Figure 6), consistent with the dramatic effect of TGF- $\beta$ neutralization in promoting aneurysm formation and progression. Interestingly, concomitant depletion of monocytes/macrophages using clodronate-liposomes abrogated the increase in gelatinolytic activity, whereas concomitant administration of PBS-liposomes had no effects (Figure 6). These results indicate that macrophage-dependent matrix-degrading activity is potentially required for aneurysm formation and progression.

$M M P-12$ is activated in mice treated with Ang II and anti-TGF- $\beta$ antibody, and significantly contributes to aneurysm progression and rupture. We then examined the involvement of MMPs in anti-TGF- $\beta$-induced matrix degradation. We found increased upregulation of MMP-9 gelatinolytic activity in abdominal aortic segments of Ang IIinfused mice treated with neutralizing anti-TGF- $\beta$ antibody (Figure 7A and Supplemental Figure 4). This was not associated with a significant change in Timp 1 or Timp 3 mRNA expression (Figure 7B). The increase in vascular MMP-9 gelatinolytic activity was already detected at day 3 after TGF- $\beta$ neutralization (Supplemental Figure 5), irrespective of the occurrence of AAA rupture. However, 

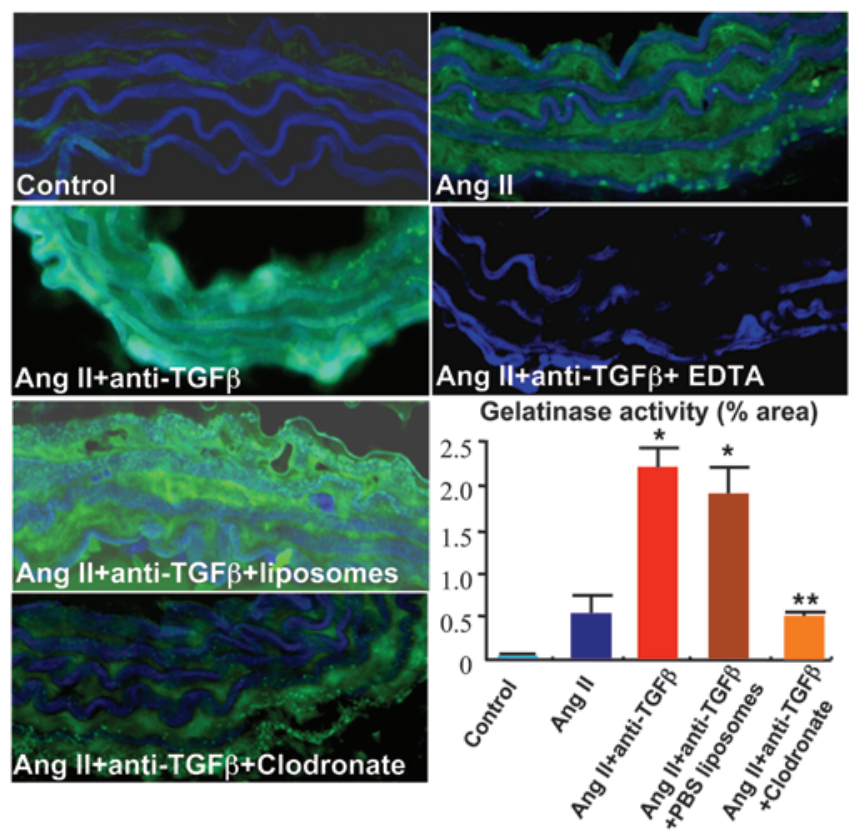

vascular MMP-12 caseinolytic activity of anti-TGF- $\beta$-treated mice increased only after day 9 of TGF- $\beta$ neutralization (Supplemental Figure 5) and was markedly upregulated in mice that died from AAA rupture (Figure $7 B$ ). Since more than $80 \%$ of AAA ruptures occurred after day 9 of high-dose anti-TGF- $\beta$ treatment (Figure 1 ), the results suggested a potential role for MMP-12 metalloelastase in aneurysm progression to rupture.

Thus, we further investigated the direct role of MMP-12 expression in AAA formation and rupture. Mmp12 deficiency substantially inhibited caseinolytic activity (Figure 7B) and was associated with an increase in aortic Timp 1 mRNA expression (Figure 7C). Aneurysms continued to form in $M m p 12$-deficient mice. However, the process was delayed, as revealed by the lack of vessel dilatation at day 14 in Mmp12-deficient mice compared with controls (Figure 7E). Most importantly, Mmp12 deficiency significantly inhibited elastin degradation (Figure 7D) and aneurysm severity (Figure 7G), which led to a complete protection from death by aneurysm rupture (Figure $7 \mathrm{H})$. These results clearly show that TGF- $\beta$ controls the progression toward aneurysm rupture, at least in part through inhibition of MMP-12 activity.

\section{Discussion}

Detailed and precise understanding of the pathophysiology of vascular aneurysm formation is a prerequisite for the development of efficient nonsurgical therapeutic strategies to limit the important burden of the disease. Initial studies highlighted the association of a chronic transmural inflammatory process with loss of medial smooth muscle cells and a destructive remodeling of the extracellular matrix as important histopathologic features of human AAAs $(27,28)$. Mechanistic studies in animal models of the disease pointed to the critical role of matrix metalloproteinases and cysteine proteases in collagen and elastin degradation, leading to medial destruction (reviewed in ref. 27). Given the role of TGF- $\beta$ in the regulation of matrix production and remodeling $(29,30)$, these studies initially suggested a theoretical protective role for this factor in limiting disease progression. This was in agreement with a

\section{Figure 6}

Neutralization of TGF- $\beta$ induces a monocyte/macrophage-dependent increase in gelatinase activity in the abdominal aorta. Representative examples and semiquantitative analysis (percent positivity relative to the whole section area) of gelatinase activity (green) in suprarenal abdominal aortas of control mice; mice infused with Ang II, either with or without anti-TGF- $\beta$; and those treated with anti-TGF- $\beta$ and either PBS- or clodronate-containing liposomes. Elastin lamellae are depicted in blue. TGF- $\beta$ neutralization led to a marked increase in gelatinase activity (typical areas with enhanced gelatinolytic activity are shown), which was significantly inhibited by depletion of monocytes/ macrophages using clodronate. EDTA in vitro completely abrogated gelatinase activity. Results are mean \pm SEM of 4-5 mice per group. Original magnification, $\times 400$. ${ }^{*} P<0.05,{ }^{*} P<0.01$.

single study showing that adenovirus-mediated overexpression of TGF- $\beta$ stabilizes already-formed aortic aneurysms in a xenotransplantation model (31). However, the precise role of endogenous TGF- $\beta$ activity in native inflammatory forms of AAAs remained unexplored, and previous assumptions about its potential protective role were challenged by the discovery that endogenous vascular TGF- $\beta$ activity is increased in patients with Marfan syndrome and contributes to vessel dilatation and aneurysm formation (6). In addition, more recent studies reported increased TGF- $\beta$ expression, retention, and/or signaling in syndromic and nonsyndromic aneurysms of the ascending aorta (12) and even in the Ang IIinduced mouse model of AAA (17) and suggested a pathogenic role for TGF- $\beta$ activity in driving aneurysm formation. Our present results clearly indicate that the recently reported pathogenic role of TGF- $\beta$ activity in Marfan syndrome cannot be extrapolated to Ang II-dependent AAA and that increased TGF- $\beta$ expression in the Ang II-induced mouse model of AAA (17) should be considered as a counterregulatory protective process that is critically required for the preservation of vessel integrity in C57BL/ 6 mice.

We then examined why the same factor, TGF- $\beta$, is detrimental for aneurysm formation in Marfan syndrome but is critically required to maintain vessel integrity in $\mathrm{C} 57 \mathrm{BL} / 6$ mice. Increased TGF- $\beta$ activity in Marfan vessels is compatible with the noninflammatory phenotype of the disease. Our hypothesis is that, in Marfan syndrome, increased TGF- $\beta$ activity during vascular development induces noninflammatory excessive accumulation of smooth muscle(-like) cells and elastin-poor extracellular matrix, leading to pathologic matrix remodeling and accelerated growth of a loose and fragile vascular wall. However, other forms of AAA in humans or in mouse models of the disease are characterized by a thin arterial wall with loss of smooth muscle cells and extracellular matrix, associated with a marked vascular inflammation. We propose that because it promotes smooth muscle cell survival, matrix preservation, and antiinflammatory activities, TGF- $\beta$ is required for the prevention of the prominent vascular inflammation, vascular cell death, and matrix degradation that characterize AAA in humans and that are recapitulated, at least to some extent, in the mouse model of Ang II-induced AAA. Our results are supported by recent observational data obtained in an experimental surgical model of thoracic aortic aneurysm, where alterations in the TGF- $\beta$ pathway have been associated with enhanced matrix degradation (32). Another potential explanation for the differential role of TGF- $\beta$ in Marfan syndrome and the present model of AAA is that the vascular effects of TGF- $\beta$ may vary according to aneurysm localization (thoracic versus abdominal) and the embryonic origin of vascular cells. This hypothesis 
A

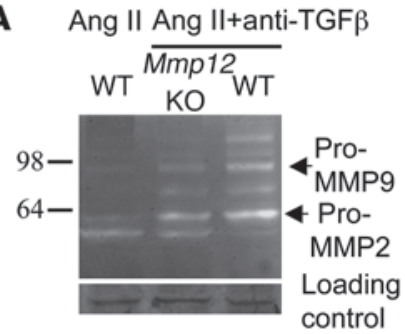

B Ang II Ang II+anti-TGF $\beta$

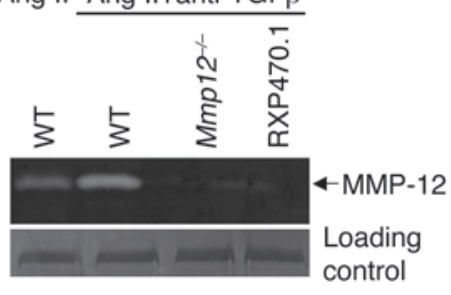

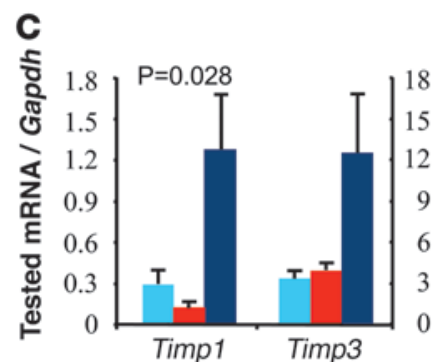

Ang II $\square$ Ang II+anti-TGF $\beta$

Ang II+anti-TGF $\beta, M m p 12^{-1-}$ mice
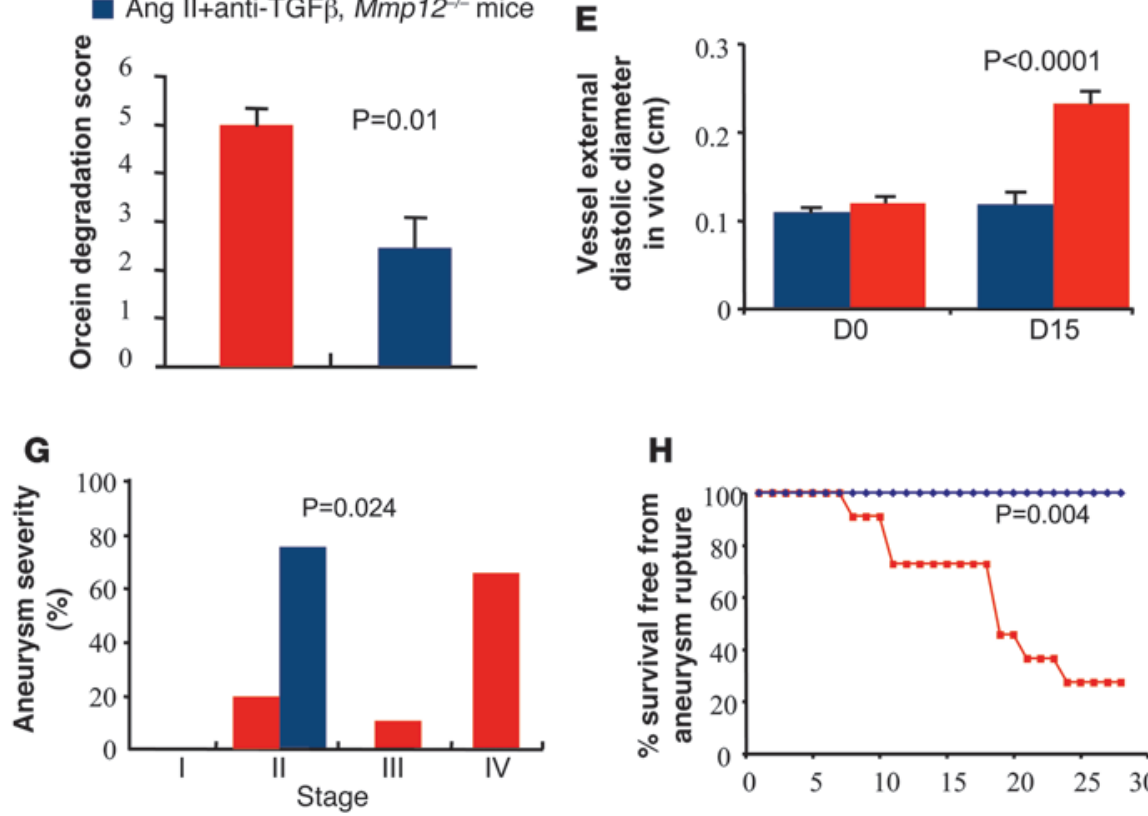

H

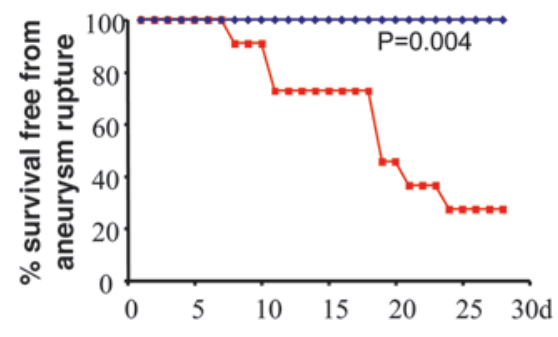

Figure 7

MMP-12 is required for aneurysm progression and rupture in mice treated with Ang II and anti-TGF- $\beta$ antibody. Representative examples of 5 separate experiments showing gelatinolytic MMP-9 and MMP-2 (A) and caseinolytic MMP-12 (B) activities in suprarenal abdominal aortas of mice infused with Ang II, with or without anti-TGF- $\beta$, and with or without genetic deficiency for Mmp12. RXP470.1 completely inhibited the caseinolytic activity, further indicating that the activity was specific for MMP-12. Loading controls represent bands obtained after Coomassie blue staining. For technical reasons, loading control of the casein zymography was run on a separate gel. (C) Quantification of aortic mRNA expression (Q-PCR) of Timp1 and Timp3 ( $n=5-6$ per group). We found a significant increase in Timp1 expression in Mmp12-deficient mice. (D) Representative examples and quantitative analysis of elastin (orcein staining) degradation (arrows) in WT and Mmp12-deficient mice infused with Ang II and treated with anti-TGF- $\beta$ antibody. Data were collected using aortic specimens recovered at day 28 or at necropsy when animal death from AAA rupture occurred before day 28. Original magnification, $\times 400$. (E) Vessel diameter in vivo using ultrasound imaging. Targeted M-mode-derived blinded measurements of aortic diameters were obtained as described in Methods at days 0 and 15 after the beginning of treatment. Vessel dilatation at the suprarenal level was abrogated at day 15 in Mmp12-deficient mice. (F-H) Quantification of aortic aneurysm incidence $(\mathbf{F})$ and severity $(\mathbf{G})$ as well as Kaplan-Meier curves of survival free from aneurysm rupture $(\mathbf{H})$ in WT and Mmp12-deficient mice. Mmp12 deficiency significantly reduced aneurysm severity and completely protected from aneurysm rupture.

merits further exploration. However, it should be noted that rupture of the thoracic aorta and intrathoracic hemorrhage occurred in $15 \%$ of anti-TGF- $\beta$-treated, Ang II-infused mice.

Our results may seem to contradict recent results by King et al. (21), who showed that administration of an anti-TGF- $\beta$ antibody did not alter AAA development in $\mathrm{Apoe}^{-/-}$mice. Unfortunately, the authors presented no data regarding the efficiency of their neutralization protocol. Using the same antibody and the dosage reported in their study, we were unable to observe any acceleration of AAA development in C57BL/6 mice. It is noteworthy that increasing the dose and the number of antibody injections in our studies resulted in increased AAA incidence and severity (Figure 1), clearly indicating that efficient neutralization of TGF- $\beta$ enhances the susceptibility to AAA.

Transmural inflammatory cell infiltration is an important feature of AAAs. Previous mechanistic studies in animal models of the disease have pointed to the important role of the immunoinflammatory response in promoting medial destruction and vessel dilatation $(14,27)$. Surprisingly, despite the fact that several studies had directly addressed the role of various inflammatory cell types in aneurysm formation, including neutrophils $(33,34)$, mast cells (26), and lymphocytes $(14,23)$, the role of monocytes/macrophages remained almost unexplored. Daugherty et al. tried to address this issue in mice with $M$-CSF deficiency (op/op mice) (35). $M$-CSF defi- 
ciency did not significantly affect AAA formation. The incidence of AAAs in $A p o e^{-/-}$mice was 14\%, 13\%, and 50\% in +/+,op/+, and op/op groups, respectively $(P>0.05)$. However, the interpretation of these results was limited by the fact that AAAs were only detected in a small number of $A p^{-/-}$mice, unlike in many other studies, including those performed by Daugherty and colleagues (16). In our present study, acute monocyte depletion using clodronate-containing liposomes did not significantly alter aneurysm incidence but profoundly reduced aneurysm severity. Partial protection was obtained by deletion of $C x 3 \mathrm{cr} 1$ and $C c l 2$, suggesting that additional chemokine pathways also contribute to disease development. Overall, our data show that monocytes play an important role in aneurysm progression rather than aneurysm initiation and that several pathogenic pathways converge in order to promote overt disease. For example, aneurysm initiation might be more dependent on neutrophil infiltration, a very early step unaffected by clodronate treatment. Future studies should delineate more precisely the role of the different monocyte subsets and chemokine pathways in aneurysm progression and identify the critical monocyte/macrophage-related factors responsible for destructive vessel remodeling.

Our present data already suggest that one of these macrophagerelated destructive factors is MMP-12. We focused more particularly on MMP-12 for several reasons. Macrophages are an important source of MMP-12, an elastin-degrading enzyme also known as the macrophage metalloelastase, required for macrophage-mediated proteolysis and matrix invasion (36). MMP-12 has been shown to be upregulated in AAA (37), and its deficiency limits calcium chlorideinduced vessel dilatation $(38,39)$, although it did not significantly alter elastase-induced aneurysm formation (40). TGF- $\beta$ potently inhibits cytokine-mediated MMP-12 induction in macrophages (41), and blockade of TGF- $\beta$ signaling dramatically upregulates MMP-12 activity $(42,43)$. Our results indicate that MMP-12 activity significantly contributes to Ang II-induced aneurysm progression in the context of TGF- $\beta$ neutralization and is critically required for full elastin degradation and vessel rupture. It is important to note that MMP-9 gelatinolytic activity was reduced in MMP-12-deficient mice, most probably reflecting reduced aneurysm severity in these animals, and might have further contributed to vascular protection. Aneurysms can still form, however, in the absence of MMP-12, suggesting that residual activity of other MMPs $(38,40,44)$ may initiate elastin degradation and aneurysm formation. This scenario is compatible with previous results showing that AAA appearance was concomitant with elastin disruption and that AAA rupture is secondary to AAA formation $(45,46)$.

An important issue is the clinical relevance of our findings. In this regard, it is noteworthy that recent studies suggested a significant association between AT1 receptor gene polymorphism and AAA in at least 3 independent cohorts (19). The ACE DD genotype has also been shown to be associated with AAA (20). Interestingly, while genetic polymorphisms in the main TGF- $\beta$ receptors could not be linked to AAA in humans $(47,48)$, a recent study has shown that the association of $A C E D D$ and TGBR1 6A polymorphisms greatly and synergistically increased the predisposition to AAA (48). Of note, the TGBR1 6A allele has been linked to impaired TGF- $\beta$ signaling (49). Thus, despite the limitations inherent to the use of an acute model with artificial infusion of Ang II in C57BL/ 6 mice, the information provided here that Ang IIdependent TGF- $\beta$ activity preserves vessel integrity might be of great clinical importance given that Ang II signaling is involved in many human disorders, including AAA.
Finally, we believe that we have set up a new simple and reproducible model of AAA in nonatherosclerotic mice. Although considered to be independent of the atherosclerotic process, AAA formation in $A p^{-/-}$mice (infused with Ang II) may still be confounded by the presence of atherosclerosis, particularly when a given intervention alters both atherosclerosis and aneurysm formation, making very difficult a reliable mechanistic interpretation of the results. The other drawback of the Apoe $e^{-/-}$model is its low reproducibility in terms of incidence and severity of AAA (see, for example, refs. $16,35)$ and the very low percentage of severe, complicated, and ruptured AAAs. Nonatherosclerotic mouse models of aneurysm formation have been developed, including calcium chloride- and elastase-induced models. Major drawbacks of these models include the need for an aggressive surgical procedure and the great difficulty in experimental protocol setup. Thus, the present new model associating Ang II infusion and systemic inhibition of TGF- $\beta$ activity in nonatherosclerotic C57BL/6 mice leads to a highly reproducible induction of severe and complicated AAAs and can be easily implemented to assess the pathophysiological pathways leading to aneurysm formation and dissection or to test novel therapeutic strategies. However, given the fact that $50 \%$ of mice die before day 15 from AAA rupture, the model will be more suitable to the testing of preventive rather than curative therapy. Finally, whether our results could extend to other models of aneurysm formation or to mice with a different genetic background remains to be explored.

In conclusion, we show that, contrary to its pathogenic role in the promotion of aneurysm development in Marfan syndrome, TGF- $\beta$ activity is critically required for protection against the development of AAA and dissection in C57BL/ 6 mice treated with Ang II. The protective effect involves a critical role for TGF- $\beta$ in the control of excessive monocyte/macrophage activation, the inhibition of matrix degradation, and the preservation of medial smooth muscle cell survival. The results clearly indicate that TGF- $\beta$ activity plays distinct roles in distinct forms of aneurysmal diseases and clearly caution against the hazardous extrapolation of results obtained in Marfan or Marfan-like diseases to the other types of aneurysm formation.

\section{Methods}

Animals and materials. Experiments were conducted according to the guidelines formulated by the European Community for experimental animal use (L358-86/609EEC) and were approved by the Ethical Committee of INSERM and by the French Ministry of Agriculture (agreement no. A75-15-32). We used male mice between 8 and 12 weeks of age. C57BL/6J Apoe ${ }^{+/+}$and Apoe $e^{-/-}$mice were from Charles River. C57BL/6J Rag2 $2^{-/-}$mice were purchased from Centre de Cryopréservation, Distribution, Typage et Archivage animal or were provided by Olivier Lantz, Institut Curie, Paris, France. C57BL/6J $I l 4^{--}$and $\mathrm{Il6} 6^{-/-}$mice were purchased from The Jackson Laboratory. Mmp $12^{-/-}$ mice were provided by Steve D. Shapiro (Brigham and Women's Hospital, Boston, Massachusetts, USA) (36) and were backcrossed 10 times into the C57BL/ 6 background. Infliximab was provided by Martine Cohen-Solal (INSERM U606, Hôpital Lariboisière, Paris, France). Neutralizing purified monoclonal rat IgG1 anti-IFN- $\gamma$ antibody (clone XMG.1) was produced by L. Rénia, and complete efficacy of this batch was previously demonstrated (50). Mouse anti-human TGF- $\beta(\beta 1, \beta 2$, and $\beta 3)$ (clone $2 \mathrm{G} 7$ ) was provided by Didier Fradelizi (Institut Cochin, Plate-forme d'imagerie du petit animal, Hôpital Cochin, Paris, France), and efficacy was demonstrated previously (51). Polyclonal rabbit anti-TGF- $\beta$ was from R\&D Systems (AB-100-NA, lot number EO16) and was previously shown to inhibit vascular TGF- $\beta$ activity (6). Angiotensin II was purchased from Sigma-Aldrich, and ALZET osmotic pumps were from Charles River Laboratories. 
The mouse model of Ang II-induced aortic aneurysm. The mouse model of Ang IIinduced aneurysm formation has been previously described (16). Ang II was infused via subcutaneous osmotic pumps at $1,000 \mathrm{ng} / \mathrm{kg} / \mathrm{min}$ for a maximum of 28 days. Aneurysm severity (stage I to stage IV) was evaluated as previously described (52). Stage IV was attributed to ruptured aneurysms. In the present study, which was initially designed to examine the role of the inflammatory response in Ang II-induced glomerulonephritis, mice received salt supplementation (5\%). However, as shown in Supplemental Figure 6, salt supplementation had no specific modulatory effect on aneurysm formation.

Ultrasound study. We used an echocardiograph (Vivid 7, GE Medical Systems ultrasound) equipped with a $12-\mathrm{MHz}$ linear transducer (12L). Data were transferred online to an ultrasound image workstation for subsequent analysis (PC EchoPAC, GE Medical Systems ultrasound).

Preparation for imaging. After sedation, the animal was shaved to increase probe contact. The ultrasound device was placed on the left abdominal side for ultrasound examination of the abdominal aorta and renal arteries as previously described $(53,54)$. Imaging depth was set at $2-3 \mathrm{~cm}$ when applying zoom; frame rate was approximately 50 frames/s. Color-coded Doppler mode was activated to help localize the renal arteries by their color-coded blood flow on the screen. The 2 segments of the abdominal aorta were distinguished, i.e., the upper renal abdominal aorta upstream from the emergence of the right renal artery and the suprarenal abdominal renal aorta downstream from the emergence of the left renal artery. In the configuration selected for color-coded Doppler ultrasound acquisition, the frequency emission was $6.7 \mathrm{MHz}$, pulsed repetition frequency set at $3.5 \mathrm{kHz}$, frame rate 37.8 frames per second, and low-velocity rejection $1.65 \mathrm{~cm} / \mathrm{s}$. The transducer was moved until the aorta was strictly parallel to the surface of the device, in order to place this vessel strictly orthogonal to the targeted M-mode line when activated. The M-mode line was placed to cross the upper renal aorta 1-3 mm up the right renal artery, then placed to cross the suprarenal aorta 1-3 mm down the left renal artery for measurement of aortic diameters in its 2 parts. Targeted M-mode-derived measurements of aortic diameters were obtained, i.e., intima-to-intima diastolic and systolic diameters as well as adventitia-to-adventitia diastolic and systolic diameters in the upper renal abdominal aorta as well as in the suprarenal abdominal aorta. In the case of upper renal aortic aneurysm, targeted M-mode-derived measurements of the aorta were made at the level of the highest dilatation of the aneurysm.

Characterization of aneurysmal lesions. Both cryostat and paraffin-embedded aortic sections were used. Elastin staining was visualized using orcein, and the number of degraded elastin lamellae was quantified by a researcher blinded to the experimental protocol. VSMCs were stained using anti- $\alpha$-actin smooth muscle cells, clone 1A4 (Sigma-Aldrich); T lymphocytes using antiCD3 antibody (Dako); and macrophages using anti-mouse CD68 antibody (Serotec). The percentage of cellular area with positive staining was quantified using Histolab software (Microvision). Apoptotic cell death was detected using TUNEL (ApopDETEK kit, ENZO Diagnostics). Phosphorylated Smad2 was detected using a specific antibody (Chemicon).

Quantitative real-time PCR. Quantitative real-time PCR (Q-PCR) was performed on an ABI Prism 7700 (Applied Biosystems) in triplicate. CT for Gapdh (primers: Gapdh R, 5'-CGTCCCGTAGACAAAATGGTGAA-3'; Gapdh L, 5'-GCCGTGAGTGGAGTCATACTGGAACA-3') was used to normalize gene expression. Primer sequences for Timp1 and Timp 3 are as follows: Timp1 R, 5'-GCCCCCTTTGCATCTCTGGCATC-3'; Timp1 L, 5'-GCGGTTCTGGGACTTGTGGGCATA-3'; Timp3 R, 5'-GGCCTCAATTACCGCTACCAC3', Timp3 L, 5'-GGCGTTGCTGATGCTCTTGT-3'.

Gelatin and casein zymography. Zymography using gelatin- or casein-containing gels was performed as described previously $(55,56)$. Briefly, modified Laemmli buffer without mercaptoethanol was added to lysed aortic samples and loaded on an SDS-polyacrylamide gel containing gelatin or casein (Bio-Rad). After electrophoresis, SDS was removed from the gel by washing twice with $2.5 \%$ Triton X-100 at room temperature. Gels were incubated in zymography buffer $(50 \mathrm{mmol} / \mathrm{l}$ Tris-HCl, $\mathrm{pH} 7.4$, and $15 \mathrm{mmol} / \mathrm{l}$ $\mathrm{CaCl}_{2}$ ) at $37^{\circ} \mathrm{C}$ for 96 hours and then stained with Coomassie brilliant blue. Gelatinolytic activity was visualized as clear bands of lysis against a dark background. In some experiments, gels were incubated in zymography buffer containing $20 \mathrm{mM}$ EDTA (Sigma-Aldrich) or $1 \mathrm{mM}$ PMSF (SigmaAldrich). In addition, RXP470.1 (100 nM), a highly specific MMP-12 inhibitor described by Devel et al. (57), was provided by Vincent Dive (Commissariat à l'Energie Atomique, Gif-sur-Yvette, France) and was used in vitro to further address the specificity of the caseinolytic band. For in situ zymography, arterial $8-\mu \mathrm{m}$ sections (cryostat) were incubated at $37^{\circ} \mathrm{C}$ for 24 hours with a fluorogenic gelatin substrate (DQ gelatin, Invitrogen) dissolved to $25 \mu \mathrm{g} / \mathrm{ml}$ in zymography buffer. Proteolytic activity was detected as green fluorescence $(530 \mathrm{~nm})$. Autofluorescent elastic laminae appeared in blue. Semiquantitative analysis of density measurements was obtained using Histolab software (Microvision), and results were expressed as percentage of surface showing positive fluorescence relative to the whole section area.

Monocyte depletion and flow cytometry. Circulating monocytes were depleted using liposomes containing clodronate (dichloromethylene diphosphonate) (ClodronateLiposomes.org). Animals received $150-\mu \mathrm{l}$ intravenous injections of clodronate- or PBS-liposomes every 3 days. Cell surface staining using flow cytometry employed the standard procedures and the following conjugated antibodies: anti-CD11b (clone M1/70), anti-Ly-6G (1A8), and allophycocyanin-conjugated anti-mouse neutrophil 7/4. Cell suspensions were incubated with appropriate fluorochrome-conjugated mAbs and run for 4-color fluorescence staining on a cytofluorometer (FACS Canto II, BD) and analyzed as previously described (58).

Cell culture and cytokine assays. Production of IL-12 and IL-10 was assessed in the supernatants of splenocyte suspensions stimulated with LPS/IFN- $\gamma$, as previously described (59).

Determination of serum TGF- $\beta$ activity. We used a solid-phase ELISA designed to measure biologically active TGF- $\beta 1$ (R\&D Systems). On the day of the assay, serum samples $(40 \mu \mathrm{l})$ were acidified to a $\mathrm{pH}$ of $2-3$ with $10 \mu \mathrm{l} 1 \mathrm{~N} \mathrm{HCl}$ for 10 minutes to activate latent TGF- $\beta$ and then reneutralized to $\mathrm{pH} 7-8$ with $8 \mu \mathrm{l} 1.2 \mathrm{~N} \mathrm{NaOH} / 0.5 \mathrm{M}$ HEPES.

Statistics. Values are expressed as percentage or mean \pm SEM when appropriate. Statistical tests included Mann-Whitney $U, \chi^{2}$, and Fisher's exact tests. Kaplan-Meier survival curves were constructed and analyzed using log-rank (Mantel-Cox) test. $P$ values of less than 0.05 were considered significant.

\section{Acknowledgments}

We are indebted to José Vilar for expert technical assistance and to Dominique Macé for animal care. Infliximab was kindly provided by Martine Cohen-Solal, INSERM U606, Hôpital Lariboisière, Paris, France. RXP470.1 was kindly provided by Vincent Dive, Commissariat à l'Energie Atomique, Centre de Saclay, Gif-surYvette, France. The MMP-12-deficient mice were originally provided by the laboratory of Steven D. Shapiro, Brigham and Women's Hospital, Boston, Massachusetts, USA. This work was supported by INSERM, by a program grant from Fondation pour la Recherche Médicale, Vieillissement Cardiovasculaire, by a Leducq Transatlantic Network grant (LINK), and by an FP7 grant (TOLERAGE). Y. Wang was supported by Société Française d'Athérosclérose.

Received for publication November 24, 2008, and accepted in revised form November 4, 2009.

Address correspondence to: Ziad Mallat, INSERM U970, Paris Cardiovascular Research Center, 56, rue Leblanc, 75015 Paris, France. Phone: 331-5398-8050; Fax: 331-5398-7952; E-mail: ziad.mallat@inserm.fr. 
1. Best VA, Price JF, Fowkes FG. Persistent increase in the incidence of abdominal aortic aneurysm in Scotland, 1981-2000. Br J Surg. 2003; 90(12):1510-1515.

2. Fleming C, Whitlock EP, Beil TL, Lederle FA. Screening for abdominal aortic aneurysm: a best-evidence systematic review for the U.S. Preventive Services Task Force. Ann Intern Med. 2005;142(3):203-211.

3. Golledge J, Muller J, Daugherty A, Norman P. Abdominal aortic aneurysm: pathogenesis and implications for management. Arterioscler Thromb Vasc Biol. 2006;26(12):2605-2613.

4. Powell JT, Brady AR. Detection, management, and prospects for the medical treatment of small abdominal aortic aneurysms. Arterioscler Thromb Vasc Biol. 2004;24(2):241-245.

5 . Golledge J, et al. Association between osteopontin and human abdominal aortic aneurysm. Arterioscler Thromb Vasc Biol. 2007;27(3):655-660.

6. Habashi JP, et al. Losartan, an AT1 antagonist, prevents aortic aneurysm in a mouse model of Marfan syndrome. Science. 2006;312(5770):117-121.

7. Neptune ER, et al. Dysregulation of TGF-beta activation contributes to pathogenesis in Marfan syndrome. Nat Genet. 2003;33(3):407-411.

8. Pannu $\mathrm{H}$, et al. Mutations in transforming growth factor-beta receptor type II cause familial thoracic aortic aneurysms and dissections. Circulation. 2005;112(4):513-520

9. Loeys BL, et al. Aneurysm syndromes caused by mutations in the TGF-beta receptor. $N$ Engl J Med. 2006;355(8):788-798

10. Nataatmadja M, West J, West M. Overexpression of transforming growth factor-beta is associated with increased hyaluronan content and impairemnt of repair in Marfan syndrome aortic aneurysm. Circulation. 2006;114(suppl 1):I371-I377.

11. Loeys B, De Paepe A. New insights in the pathogenesis of aortic aneurysms. Verh K Acad Geneeskd Belg. 2008;70(2):69-84.

12. Gomez D, et al. Syndromic and non-syndromic aneurysms of the human ascending aorta share activation of the Smad2 pathway. J Pathol. 2009;218(1):131-142.

13. Daugherty A, Cassis LA. Mouse models of abdominal aortic aneurysms. Arterioscler Thromb Vasc Biol. 2004;24(3):429-434.

14. Shimizu K, Mitchell RN, Libby P. Inflammation and cellular immune responses in abdominal aortic aneurysms. Arterioscler Thromb Vasc Biol. 2006;26(5):987-994.

15. Curci JA, Thompson RW. Adaptive cellular immunity in aortic aneurysms: cause, consequence, or context? J Clin Invest. 2004;114(2):168-171.

16. Daugherty A, Manning MW, Cassis LA. Angiotensin II promotes atherosclerotic lesions and aneurysms in apolipoprotein E-deficient mice. J Clin Invest. 2000;105(11):1605-1612.

17. Rush C, Nyara M, Moxon JV, Trollope A, Cullen $\mathrm{B}$, Golledge J. Whole genome expression analysis within the angiotensin II-apolipoprotein E deficient mouse model of abdominal aortic aneurysm. BMC Genomics. 2009;10:298.

18. Daugherty A, Manning MW, Cassis LA. Antagonism of AT2 receptors augments angiotensin IIinduced abdominal aortic aneurysms and atherosclerosis. BrJ Pharmacol. 2001;134(4):865-870.

19. Jones GT, et al. Angiotensin II type 1 receptor $1166 \mathrm{C}$ polymorphism is associated with abdominal aortic aneurysm in three independent cohorts. Arterioscler Thromb Vasc Biol. 2008; 28(4):764-770.

20. Fatini C, et al. ACE DD genotype: a predisposing factor for abdominal aortic aneurysm. Eur J Vasc Endovasc Surg. 2005;29(3):227-232.

21. King VL, et al. Interferon-gamma and the interferon-inducible chemokine CXCL10 protect against aneurysm formation and rupture. Circulation.
2009;119(3):426-435.

22. Gorelik L, Flavell RA. Transforming growth factor-beta in T-cell biology. Nat Rev Immunol. 2002;2(1):46-53

23. Xiong W, Zhao Y, Prall A, Greiner TC, Baxter BT. Key roles of CD4+ T cells and IFN-gamma in the development of abdominal aortic aneurysms in a murine model. J Immunol. 2004;172(4):2607-2612.

24. Shimizu K, Shichiri M, Libby P, Lee RT, Mitchell $\mathrm{RN}$. Th2-predominant inflammation and blockade of IFN-gamma signaling induce aneurysms in allografted aortas. J Clin Invest. 2004;114(2):300-308.

25. Han Y, Runge MS, Brasier AR. Angiotensin II induces interleukin- 6 transcription in vascular smooth muscle cells through pleiotropic activation of nuclear factor-kappa B transcription factors. Circ Res. 1999;84(6):695-703.

26. Sun J, et al. Mast cells modulate the pathogenesis of elastase-induced abdominal aortic aneurysms in mice. J Clin Invest. 2007;117(11):3359-3368.

27. Thompson RW, Geraghty PJ, Lee JK. Abdominal aortic aneurysms: basic mechanisms and clinical implications. Curr Probl Surg. 2002;39(2):110-230.

28. Wassef M, Upchurch GRJr, Kuivaniemi H, Thompson RW, Tilson MD III. Challenges and opportunities in abdominal aortic aneurysm research. $J$ Vasc Surg. 2007;45(1):192-198.

29. Roberts AB, et al. Transforming growth factor type beta: rapid induction of fibrosis and angiogenesis in vivo and stimulation of collagen formation in vitro. Proc Natl Acad Sci U S A. 1986;83(12):4167-4171.

30. Bobik A. Transforming growth factor-betas and vascular disorders. Arterioscler Thromb Vasc Biol. 2006;26(8):1712-1720.

31. Dai J, et al. Overexpression of transforming growth factor-beta 1 stabilizes already-formed aortic aneurysms: a first approach to induction of functional healing by endovascular gene therapy. Circulation. 2005;112(7):1008-1015.

32. Jones JA, et al. Altered transforming growth factorbeta signaling in a murine model of thoracic aortic aneurysm. J Vasc Res. 2008;45(6):457-468.

33. Eliason JL, et al. Neutrophil depletion inhibits experimental abdominal aortic aneurysm formation. Circulation. 2005;112(2):232-240.

34. Pagano MB, et al. Critical role of dipeptidyl peptidase I in neutrophil recruitment during the development of experimental abdominal aortic aneurysms. Proc Natl Acad Sci U S A. 2007;104(8):2855-2860.

35. Babamusta F, Rateri DL, Moorleghen JJ, Howatt DA, Li XA, Daugherty A. Angiotensin II infusion induces site-specific intra-laminar hemorrhage in macrophage colony-stimulating factor-deficient mice. Atherosclerosis. 2006;186(2):282-290.

36. Shipley JM, Wesselschmidt RL, Kobayashi DK, Ley TJ, Shapiro SD. Metalloelastase is required for macrophage-mediated proteolysis and matrix invasion in mice. Proc Natl Acad Sci U S A 1996;93(9):3942-3946.

37. Curci JA, Liao S, Huffman MD, Shapiro SD, Thompson RW. Expression and localization of macrophage elastase (matrix metalloproteinase12) in abdominal aortic aneurysms. J Clin Invest. 1998;102(11):1900-1910.

38. Longo GM, Xiong W, Greiner TC, Zhao Y, Fiotti N, Baxter BT. Matrix metalloproteinases 2 and 9 work in concert to produce aortic aneurysms. J Clin Invest. 2002;110(5):625-632

39. Longo GM, et al. MMP-12 has a role in abdominal aortic aneurysms in mice. Surgery. 2005;137(4):457-462.

40. Pyo R, et al. Targeted gene disruption of matrix metalloproteinase-9 (gelatinase B) suppresses development of experimental abdominal aortic aneurysms. J Clin Invest. 2000;105(11):1641-1649.

41. Feinberg MW, et al. Transforming growth factor-beta 1 inhibits cytokine-mediated induction of human metalloelastase in macrophages. J Biol
Chem. 2000;275(33):25766-25773

42. Bonniaud P, et al. Smad3 null mice develop airspace enlargement and are resistant to TGFbeta-mediated pulmonary fibrosis. J Immunol. 2004;173(3):2099-2108

43. Wang X, et al. Dysregulation of TGF-beta1 receptor activation leads to abnormal lung development and emphysema-like phenotype in core fucose-deficient mice. Proc Natl Acad Sci U S A. 2005;102(44):15791-15796

44. Ikonomidis JS, et al. Effects of deletion of the matrix metalloproteinase 9 gene on development of murine thoracic aortic aneurysms. Circulation. 2005;112(9 Suppl):I242-I248.

45. Saraff K, Babamusta F, Cassis LA, Daugherty A. Aortic dissection precedes formation of aneurysms and atherosclerosis in angiotensin II-infused, apolipoprotein E-deficient mice. Arterioscler Thromb Vasc Biol. 2003;23(9):1621-1626.

46. Barisione C, Charnigo R, Howatt DA, Moorleghen JJ, Rateri DL, Daugherty A. Rapid dilation of the abdominal aorta during infusion of angiotensin II detected by noninvasive high-frequency ultrasonography. J Vasc Surg. 2006;44(2):372-376.

47. Golledge J, et al. Possible association between genetic polymorphisms in transforming growth factor beta receptors, serum transforming growth factor beta 1 concentration and abdominal aortic aneurysm. BrJ Surg. 2009;96(6):628-632.

48. Lucarini $\mathrm{L}$, et al. ACE and TGFBR1 genes interact in influencing the susceptibility to abdominal aortic aneurysm. Atherosclerosis. 2009;202(1):205-210.

49. Pasche B, et al. TbetaR-I(6A) is a candidate tumor susceptibility allele. Cancer Res. 1999; 59(22):5678-5682.

50. Rottman M, et al. IFN-gamma mediates the rejection of haematopoietic stem cells in IFN-gammaR1-deficient hosts. PLoS Med. 2008;5(1):e26.

51. Mallat $Z$, et al. Inhibition of transforming growth factor-beta signaling accelerates atherosclerosis and induces an unstable plaque phenotype in mice. Circ Res. 2001;89(10):930-934

52. Manning MW, Cassis LA, Daugherty A. Differential effects of doxycycline, a broad-spectrum matrix metalloproteinase inhibitor, on angiotensin II-induced atherosclerosis and abdominal aortic aneurysms. Arterioscler Thromb Vasc Biol. 2003;23(3):483-488.

53. Bonnin P, Sabaa N, Flamant M, Debbabi H, Tharaux PL. Ultrasound imaging of renal vaso-occlusive events in transgenic sickle mice exposed to hypoxic stress. Ultrasound Med Biol. 2008;34(7):1076-1084.

54. Sabaa N, et al. Endothelin receptor antagonism prevents hypoxia-induced mortality and morbidity in a mouse model of sickle-cell disease. J Clin Invest. 2008;118(5):1924-1933

55. Meng X, Mavromatis K, Galis ZS. Mechanical stretching of human saphenous vein grafts induces expression and activation of matrix-degrading enzymes associated with vascular tissue injury and repair. Exp Mol Pathol. 1999;66(3):227-237.

56. Lehoux S, Lemarie CA, Esposito B, Lijnen HR, Tedgui A. Pressure-induced matrix metalloproteinase- 9 contributes to early hypertensive remodeling. Circulation. 2004;109(8):1041-1047.

57. Devel L, et al. Development of selective inhibitors and substrate of matrix metalloproteinase-12.J Biol Chem. 2006;281(16):11152-11160.

58. Combadiere $\mathrm{C}$, et al. Combined inhibition of CCL2, CX3CR1 and CCR5 abrogates Ly6C(hi) and Ly6C(lo) monocytosis and almost abolishes atherosclerosis in hypercholesterolemic mice. Circulation. 2008;117(13):1649-1657.

59. Ait-Oufella $\mathrm{H}$, et al. Lactadherin-deficiency induces apoptotic cell accumulation, alters the regulatory immune response, and accelerates atherosclerosis in mice. Circulation. 2007;115(16):2168-2177. 